\title{
PERANAN WANITA TANI DALAM PENINGKATAN EKONOMI \\ PADA KEGIATAN PENGEMBANGAN USAHA MINA PEDESAAN PERIKANAN BUDIDAYA (PUMP-PB) DI KABUPATEN BULUKUMBA
}

(The Role of Farming Women in Economic Improvement in the Development of Rural Mina Business in Aquaculture (PUMP-PB) in Bulukumba Regency)

\author{
Rosliawati Arfah 1) Ilmiah 2) dan Harlina 2) \\ 1) Dinas Kelautan dan Perikanan Provinsi Sulawesi Selatan \\ 2) Dosen Program Studi Budidaya Perairan FPIK-UMI Makassar
}

Korespondensi: rosliawatyarfah@yahoo.com

Diterima: 15 Agustus 2020; Disetujui 20 November 2020

\begin{abstract}
This research aims to determine the role female farmers in development of rural aquaculture and the factors that influence the role of women farmers in rural aquaculture Development. This research was conducted in January to February 2020 in Bulukumba Regency. The t test analysis method was the comparative test. The results indicate that the Role of Women Farmers in the Development of Rural Aquaculture in Bulukumba Regency had a positive impact and the average income of the groups receiving assistance had increased incomes. The results of the calculation of multiple regression analysis show that the factors that influence the role of women farmers in the economic improvement was age, degree level, land area, and level of experience, while the nature of work and the number of dependents do not directly affect the increase in income of farmers in economic improvement activities.
\end{abstract}

Keyword: Farmer Woman; Rural Aquaculture; Development; aquaculture group

\begin{abstract}
ABSTRAK
Penelitian ini bertujuan untuk mengetahui peran wanita tani pada kegiatan pengembangan Usaha Mina Pedesaan Perikanan Budidaya dan faktor-faktor yang mempengaruhi peranan wanita tani pada kegiatan Pengembangan Usaha Mina Pedesaan Perikanan Budidaya (PUMP-PB). Penelitian ini diakukan pada bulan Januari sampai Bulan Februari Tahun 2020 di Kabupaten Bulukumba. Metode analisis uji t yaitu uji komperatif. Hasil penelitian menunjukkan bahwa Peranan Wanita Tani dalam Pengembangan Usaha Mina Pedesaan Perikanan Budidaya (PUMPPB) di Kabupaten Bulukumba memberikan dampak positif dan pendapatan rata-rata kelompok yang menerima bantuan mengalami peningkatan pendapatan. Hasil perhitungan analisis regresi berganda menunjukkan bahwa Faktor-faktor yang mempengaruhi peranan wanita tani terhadap Peningkatan Ekonomi pada kegiatan PUMP-PB adalah : umur, tingkat pendidikan, jam kerja, luas lahan, dan tingkat pengalaman, sedangkan sifat pekerjaan dan jumlah tanggungan tidak berpengaruh langsung terhadap peningkatan pendapatan wanita tani pada kegiatan PUMP - PB.
\end{abstract}

Kata Kunci : Wanita Tani; Pengembangan; Usaha Mina Pedesaan; Kelompok Pembudidaya 


\section{PENDAHULUAN}

Potensi sumberdaya perikanan tani keluarga sendiri baik sebagai khususnya pada lahan perikanan darat. tenaga kerja maupun tenaga kerja luar Luas lahan perikanan darat di keluarga(Kusnadi, 2013).

Kabupaten Bulukumba mencapai 9.500 ha dengan presentase luas terbesar terdapat pada lahan air tawar atau kolam yang mencapai $5.500 \mathrm{Ha}$, dan yang terealisasi sebesar 128,3 Ha, sedangkan luas tambak mencapai 4.000 Ha, terealisasi sebesar 3.875,6 Ha, untuk potensi rumput laut 12.400 Ha, dan yang terealisasi mencapai 7.085 Ha. (Buku Laporan Statistik DKP SulSel tahun 2018 ) Selain itu masyarakat pesisir telah lama mengelola tambak dan menjadi nelayan sehingga dari aspek keterampilan sangat terampil.

Kawasan pesisir tidak hanya didasari oleh pertimbangan pemikiran bahwa kawasan itu tidak hanya memiliki potensi sumber daya alam yang cukup besar, tetapi juga potensi sosial masyarakat yang akan mengelola sumber daya alam tersebut secara berkelanjutan. Salah satu unsur potensi sosial tersebut adalah kaum perempuan pesisir atau istri nelayan seperti peran perempuan petani dalam menutupi kekurangan kebutuhan keluarga, istri bekerja di dalam usaha
Sebagian besar kegiatan ekonomi yang dimasuki oleh kaum perempuan pesisir, istri nelayan, di sektor pengolahan hasil ikan, seperti industri pemindangan, pengeringan ikan, perdagangan ikan segar, dan pembuatan petis. Kaum perempuan juga bekerja di industri rumah tangga pembuatan kerupuk ikan dan rengginang, yang menggunakan bahan baku ikan laut. Selebihnya, mereka bekerja di sektor jasa, seperti menjadi buruh dan membuka took yang menjual barang-barang kebutuhan konsumsi penduduk setempat.

Berkaitan dengan pengerahan sumber daya ekonomi Kementerian Kelautan dan Perikanan Tahun 20112015 melaksanakan Program Pengembangan Usaha Mina Perdesaan Perikanan Budidaya (PUMP-PB), dilatarbelakangi bahwa kondisi sosial ekonomi masyarakat pesisir pantai khususnya yang bermata pencaharian petambak dan nelayan tradisional masih tergolong miskin. 
Dilihat dari kedudukannya dalam aktivitas pekerjaan-pekerjaan di atas, perempuan pesisir bisa berperan sebagai pemilik usaha atau sebagai pekerja. Sebagian besar kaum perempuan memerankan diri sebagai pekerja di sektor usaha, Oleh karena itu, perlu dilakukan penelitian yang mengkaji tentang "Peranan Wanita Tani dalam Peningkatan Ekonomi pada Kegiatan Pengembangan Usaha Mina Pedesaan Perikanan Budidaya (PUMP-PB) di Kabupaten

Bulukumba.

\section{MATERI DAN METODE}

\section{Lokasi dan Waktu Penelitian}

Penelitian ini telah dilaksanakan pada bulan Januari sampai Bulan jelasnya dapat dilihat pada gambar 2 . Februari 2020, lokasi penelitian berada
Penelitian ini bertujuan untuk mengetahui peranan wanita tani dan faktor-faktor yang mempengaruhi peranan wanita tani pada kegiatan Pengembangan Usaha Mina Pedesaan Perikanan Budidaya (PUMP-PB) di Kabupaten Bulukumba dalam peningkatan ekonomi keluarga. Selain itu penelitian ini diharapkan menjadi bahan masukan pada Pemerintah Kabupaten Bulukumba tentang arti penting peranan wanita tani dalam peningkatan ekonomi pada sektor Perikanan.

di empat (4) Kecamatan yaitu Kec. Rilau Ale, Kec. Ujung Loe, Kec. Ujung Bulu dan Kec. Gantarang. Untuk lebih

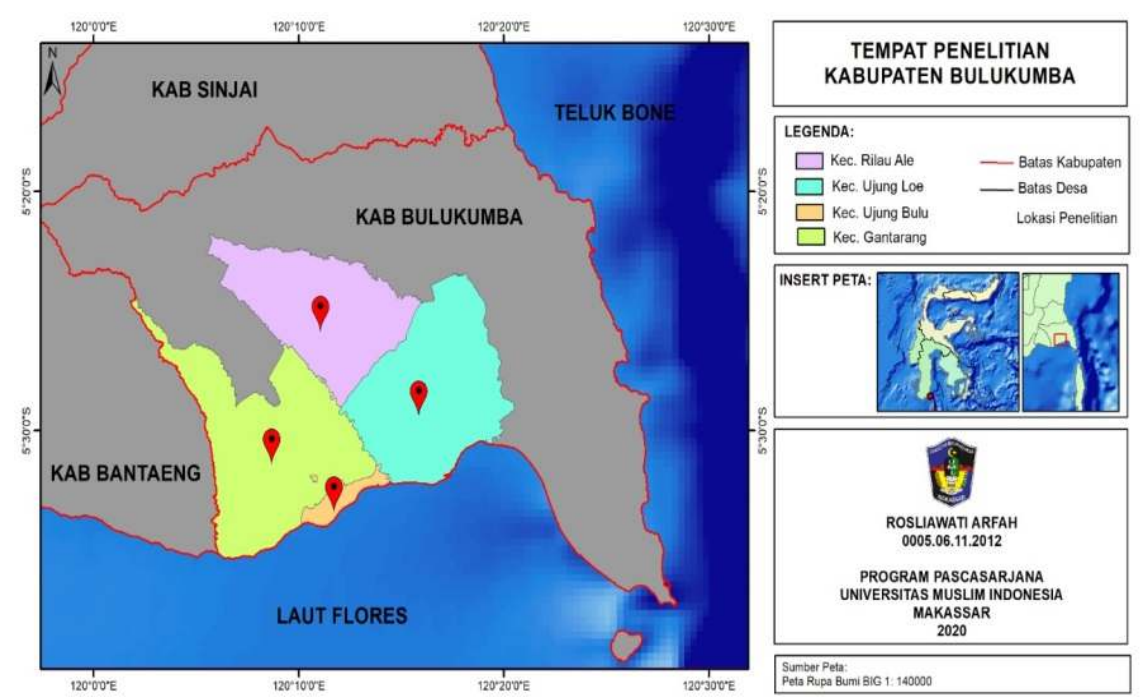

Gambar 2. Lokasi Penelitian di Kabupaten Bulukumba 


\section{Bahan dan Alat}

Adapun bahan dan alat yang digunakan dalam penelitian ini antara lain kuesioner, komputer/laptop, kamera, alat tulis menulis serta peralatan lainnya yang digunakan dan membantu dalam pengumpulan dan pengolahan data.

\section{Jenis dan Sumber Data}

Jenis data yang digunakan pada penelitian ini adalah data primer dan data sekunder baik bersifat kuantitatif maupun kualitatif. Data primer diperoleh dari responden yaitu kelompok masyarakat penerima bantuan program Pengembangan Usaha Mina Pedesaan Perikanan Budidaya (PUMP-PB), fasilitator Penyuluh Perikanan PNS/ Bantu dan Tokoh Masyarakat. Sedangkan data sekunder di peroleh dari statistik dan Dinas Perikanan Kabupaten Bulukumba serta laporan hasil penelitian yang pernah dilakukan sebelumnya dan berbagai informasi lainnya yang relevan dengan tujuan penelitian.

\section{Teknik Pengumpulan Data}

Data yang digunakan dalam penelitian ini adalah data primer dan data sekunder. Data primer diperoleh dari hasil wawancara langsung dan observasi.

Data sekunder diperoleh dari studi pustaka menyangkut dokumen kegiatan. Pengembangan Usaha Mina Pedesaan Perikanan Budidaya (PUMPPB), kantor Badan Pusat Statistik, Dinas Perikanan Provinsi Sulawesi Selatan dan data penunjang lainnya yang diperoleh melalui instansi-instansi terkait seperti Kantor kecamatan dan Kelurahan.

\section{Populasi dan Sampel}

Populasi dalam penelitian ini adalah semua wanita tani yang masuk dalam pengurus atau anggota kelompok pembudidaya penerima Bantuan Langsung Masyarakat Pengembangan Usaha Mina Pedesaan dan responden dipilih secara sengaja (Purposive Sampling Method). Pengambilan responden yaitu melibatkan wanita tani tambak dalam kegiatan tersebut yang akan dibagi dalam beberapa kecamatan dan besarnya responden disesuaikan dengan keragaman populasi, pada kelompok penerima Bantuan Langsung Tunai (BLM) PUMP-PB. 
Analisis Data

Analisis data yang digunakan disesuaikan dengan tujuan penelitian untuk menjawab tujuan pertama ; Menggunakan analisis deskriftif,

\section{HASIL DAN PEMBAHASAN}

1. Peranan wanita tani pada kegiatan Pengembangan Usaha Mina Pedesaan Perikanan Budidaya (PUMP-PB)

Kabupaten

Bulukumba

memiliki usaha perikanan di pesisir yaitu budidaya ikan, pengolahan dan pemasaran hasil panen. Usaha perikanan di Bulukumba bagian pesisir tersebar di empat kecamatan sekaligus penerima bantuan PUMP-PB yaitu Kecamatan Gantarang, Rilau Ale, Ujung Bulu, dan Ujung Loe. Keterlibatan kaum wanita (istri) dalam kegiatan perekonomian dapat dibedakan menjadi peran dalam kegiatan perekonomian rumah tangga serta perannya secara spesifik dalam pengelolaan usaha budidaya, pengolahan hasil pasca panen serta pemasaran hasil panen.

\section{- Kecamatan Gantarang}

Pada Kecamatan Gantarang sebagian besar warga kaum wanita
Sedangkan tujuan kedua menggunakan Analisis Regresi (Uji Koefisien Determinasi $\left(\mathrm{R}^{2}\right), \quad \mathrm{Uji}$ Koefisien Korelasi (r), Uji F (Uji Regresi secara Keseluruhan), dan Uji t (Uji Regresi secara Individual). terjun dalam mengolah potensi hasil perikanan budidaya udang menjadi rempeyek udang. Hal hasil udangudang hasil budidaya yang telah disulap menjadi rempeyak udang yang dapat memberikan hasil lebih baik ketimbang udang hasil penen langsung dipasarkan. Berdasarkan data Badan Pusat Statistik 2019, Kecamatan Gantarang adalah salah satu pengolah hasil perikanan sebagai pemasar hasil perikanan ikan segar dan udang.

\section{- Kecamatan Rilau Ale}

Pada Kecamatan Rilau Ale usaha bubdidaya ikan lele menjadi sumber perekonomin sebagian masyarakat atau kelompok. Melalui partisipasi pemerintah kepada sejumlah pengusaha budidaya sehingga mampu memberikan hasil yang lebih baik dan jumlah produksi meningkat. Usaha budidaya dikelolah bersama oleh kaum pria dan wanita. Mereka bekerja sama dalam hal pembagian tugas pada usaha 
budidaya seperti kaum pria menyiapkan menyortir, mengolah sampai lahan budidaya dan pada proses panen, pemasaran hasil panen.

sedangkan kaum wanita memberi makan ikan budidaya, pengolahan hasil hingga pasarkan hasil panen.

\section{- Kecamatan Ujung Bulu}

Kecamatan Ujung Bulu terdapat 4 kelurahan diantaranya 2 kelurahan yang memiliki usaha perikanan yaitu Kelurahan Bintarore dan Kelurahan Kalumeme usaha budidaya tambak ikan. Usaha budidaya tambak ikan di Kelurahan Bintarore mempunyai hasil yang baik dikembangkan sehingga pemerintah turun tangan memberikan arahan mengelolah usaha budidaya tambak ikan dengan baik. Usaha ini adalah salah satu usaha mata pencarian masyarakat yang memerlukan tenaga banyak artinya bahwa usaha ini tidak hanya bergantung oleh kepala keluarga saja melainkan ikut melibatkan seluruh anggota keluarga yang dewasa. Pada kegiatan pemanenan dibutuhkan tenaga kerja yang lebih banyak untuk mempercepat pemanenan, tetapi pada proses hampir tidak ada wanita yang berperan. Sementara pada perkerjaan kaum wanita (istri) kontribusi peran perempuan cukup besar, seperti kegiatan pasca panen yang meliputi

\section{- Kecamatan Ujung Loe}

Kecamatan ujung loe terdapat 12 kelurahan yang terdapat 12 kelompok pembudidaya. Usaha budidaya diantaranya budidaya udang dan ikan bandeng. Usaha ini memiliki potensi keberhasilan dan pasar yang cukup luas. Adanya dukungan pemerintah dalam tahap pengembangan usaha budidaya ini lebih memacu semangat para pelaku pembudidaya. Pengelolaan usaha ini masih di lakukan oleh anggota keluarga yang terdiri dari para kepala keluarga dan para wanita (istri). Biasanya pekerjaan yang dilakukan oleh pria atau kepala keluarga yaitu penyiapan lahan, penyiapan pupuk dan benih ikan. Sementara pada perkerjaan yang dapat dilakukan oleh wanita (istri), seperti kegiatan mengelolah keuangan modal, memberi makan, pengolahan hasil hingga pasarkan hasil panen.

Pada usaha perikanan di beberapa Kecamatan diatas menjelaskan bahwa kaum wanita disamping berperan dalam kegiatan rumah tangga juga berperan dalam 
setiap kegiatan ekonomi rumah tangga melakukan pekerjaan tersebut. Nurlaili dan mampun meningkatkan ekonomi dan Muhartono (2017) bahwa peran rumah tangga. Banyaknya peran istri perempuan pesisir juga terlihat dalam merupakan pencirian keluarga pengolahan hasil perikanan, dimana pedesaan, yang perekonomian keluarga mereka menjadi pelaku utama dalam tidak hanya bergantung pada kepala mengelola usaha pengeringan ikan, dan keluarga, tetapi juga para wanita (istri) pembuatan terasi sampai pada maupun anggota keluarga dewasa. pemasaran hasilnya. Selain itu peran Peran wanita dalam pengelolaan usaha wanita yang sangat penting dalam perikanan lebih didasarkan sebagai sebuah usaha adalah bagaimana sumber tenaga kerja yang diperlukan mengelola keuangan. Kusnadi (2001) dalam pengelolaan usaha keluarga menyebutkan bahwa makin sesuai dengan aksesibilitas yang menguatnya kedudukan perempuan dimilikinya. Hal ini terlihat. walaupun dalam aktivitas ekonomi terjadi sebagai pada kegiatan merawat, mengolah dan reaksi terhadap kemiskinan yang pemanenan dibutuhkan tenaga kerja disebabkan oleh kebijakan modernisasi yang lebih banyak untuk memberikan perikanan yang berdampak pada hasil yang lebih baik tetapi tidak semua penurunan kualitas sumber daya.

wanita (istri) perikanan dapat

Tabel 1.Faktor pengaruh peranan wanita tani pada subsektor perikanan dalam menunjang peningkatan ekonomi masyarakat pesisir

\begin{tabular}{|c|c|c|c|c|c|c|}
\hline & \multirow{2}{*}{ Model } & \multicolumn{2}{|c|}{$\begin{array}{c}\text { Unstandardized } \\
\text { Coefficients }\end{array}$} & \multirow{2}{*}{$\begin{array}{c}\begin{array}{c}\text { Standardized } \\
\text { Coefficients }\end{array} \\
\text { Beta }\end{array}$} & \multirow{2}{*}{$\mathrm{t}$} & \multirow{2}{*}{ Sig. } \\
\hline & & B & $\begin{array}{l}\text { Std. } \\
\text { Error }\end{array}$ & & & \\
\hline \multirow[t]{8}{*}{1} & (Constant) & $-1,350$ & ,446 & & $-3,027$ &, 003 \\
\hline & Umur &, 154 &, 070 &, 178 & 2,213 &, 029 \\
\hline & Pendidikan &, 152 & 067 & , 170 & 2,275 &, 025 \\
\hline & Jam Kerja &, 375 &, 182 &, 165 & 2,063 &, 042 \\
\hline & $\begin{array}{l}\text { Sifat } \\
\text { Pekerjaan }\end{array}$ & ,003 & , 192 &, 001 & 017 & ,987 \\
\hline & $\begin{array}{l}\text { Jumlah } \\
\text { Tanggungan }\end{array}$ & , 156 &, 116 & , 101 & 1,345 & ,182 \\
\hline & Luas Lahan &, 550 &, 095 & ,462 & 5,801 &, 000 \\
\hline & $\begin{array}{l}\text { Tingkat } \\
\text { Pengalaman }\end{array}$ & 231 & , 109 & , 194 & 2,116 & ,037 \\
\hline \multicolumn{7}{|c|}{ a. Dependent Variable: Pendapatan } \\
\hline
\end{tabular}


2. Pengaruh Umur Terhadap Pendapatan Pengembangan Usaha Mina Pedesaan Perikanan Budidaya ( PUMP-PB ) di Kab. Bulukumba.

Berdasarkan tabel di atas dapat dilihat bahwa variabel umur memiliki t hitung sebesar 2,213 > t tabel sebesar 1,9861 dengan koefisien beta unstandardized sebesar 0,154 dan tingkat signifikansi 0,029 yang lebih kecil dari 0,05. Hal ini menunjukkan bahwa umur berpengaruh terhadap pendapatan Pengembangan Usaha Mina Pedesaan perikanan budidaya ( PUMPPB ) di Kabupaten Bulukumba. Menurut Sudaryanti (2009) menunjukkan, salah satu faktor yang mempengaruhi keterlibatan wanita dalam kegiatan ekonomi adalah faktor umur, semakin bertambahnya usia seseorang akan semakin tinggi waktu kerjanya. Namun pada usia tertentu waktu kerjanya akan menurun sejalan dengan kekuatan fisik yang semakin menurun pula dan usia wanita juga mempengaruhi partisipasi dalam kegiatan ekonomi.

3. Pengaruh Pendidikan Terhadap Pendapatan Pengembangan Usaha Mina Pedesaan Perikanan Budidaya ( PUMP-PB ) di Kab. Bulukumba.
Berdasarkan tabel di atas dapat dilihat bahwa variabel pendidikan memiliki t hitung sebesar 2,275 $>\mathrm{t}$ tabel sebesar 1,9861 dengan koefisien beta unstandardized sebesar 0,152 dan tingkat signifikansi 0,025 yang lebih kecil dari 0,05. Hal ini menunjukkan bahwa pendidikan berpengaruh terhadap pendapatan Pengembangan Usaha Mina Pedesaan perikanan budidaya (PUMPPB) di Kabupaten Bulukumba. Pendidikan wanita menentukan kesempatan dan jenis pekerjaan. Kesempatan kerja untuk mereka yang berpendidikan rendah tidak banyak, dimana mereka hanya dapat bekerja sebagai buru (Soepono, 2009).

\section{Pengaruh Jam kerja Terhadap Pendapatan Pengembangan Usaha Mina Pedesaan Perikanan Budidaya ( PUMP-PB ) di Kab. Bulukumba.}

Berdasarkan tabel di atas dapat dilihat bahwa variabel jam kerja memiliki t hitung sebesar 2,063 $>\mathrm{t}$ tabel sebesar 1,9861 dengan koefisien beta unstandardized sebesar 0,375 dan tingkat signifikansi 0,042 yang lebih kecil dari 0,05. Hal ini menunjukkan bahwa jam kerja berpengaruh terhadap pendapatan Pengembangan Usaha Mina 
Pedesaan perikanan budidaya (PUMP- perempuan melakukan sosialisasi, PB) di Kabupaten Bulukumba. Studi aktualisasi diri dan terjun dalam dunia Stoller dan Hart dalam Suratiyah pekerjaan untuk mengembangkan (1991), menunjukkan bahwa tingkat pendidikan serta potensi yang penghasilan keluarga mempengaruhi pengaturan waktu. Pekerja wanita dari rumah tangga berpenghasilan rendah cenderung untuk menggunakan lebih banyak waktunya untuk aktivitas produktif dibandingkan wanita dari rumah tangga yang berpenghasilan lebih tinggi.

\section{Pengaruh Sifat Pekerjaan Terhadap Pendapatan Pengembangan Usaha Mina Pedesaan Perikanan Budidaya (PUMP-PB) di Kab. Bulukumba.}

Berdasarkan tabel di atas dapat dilihat bahwa variabel sifat pekerjaan memiliki t hitung sebesar $0,017<\mathrm{t}$ tabel sebesar 1,9861 dengan koefisien beta unstandardized sebesar 0,003 dan tingkat signifikansi 0,987 yang lebih besar dari 0,05. Hal ini menunjukkan bahwa sifat pekerjaan tidak berpengaruh terhadap pendapatan Pengembangan Usaha Mina Pedesaan Perikanan Budidaya (PUMP- PB) di Kabupaten Bulukumba. Saat ini sudah banyak wanita yang bekerja di luar rumah untuk memenuhi kebutuhan baik untuk dirinya maupun untuk keluarganya, kaum dimilikinya.

\section{Pengaruh Jumlah tanggungan Terhadap Pendapatan Pengembangan Usaha Mina Pedesaan Budidaya (PUMP-PB) di Kab. Bulukumba.}

Berdasarkan tabel di atas dapat dilihat bahwa variabel jumlah tanggungan memiliki $\mathrm{t}$ hitung sebesar $1,345<\mathrm{t}$ tabel sebesar 1,9861 dengan koefisien beta unstandardized sebesar 0,156 dan tingkat signifikansi 0,182 yang lebih besar dari 0,05. Hal ini menunjukkan bahwa jumlah tanggungan tidak berpengaruh terhadap pendapatan Pengembangan Usaha Mina Pedesaan Perikanan Budidaya (PUMP-PB) di Kabupaten Bulukumba. Jumlah anggota keluarga akan mempengaruhi curahan kerja ibu rumah tangga. Jumlah anggota keluarga dan komposisinya mempengaruhi curahan waktu kerja rumah tangga untuk mendapatkan penghasilan yang lebih tinggi guna memenuhi kebutuhan keluarganya yang semakin meningkat (Irawan, 1998). 
7. Pengaruh Luas lahan Terhadap Pendapatan Pengembangan Usaha Mina Pedesaan Perikanan Budidaya ( PUMP-PB)

Berdasarkan tabel di atas dapat dilihat bahwa variabel luas lahan memiliki thitung sebesar 5,801 $>\mathrm{t}$ tabel sebesar 1,9861 dengan koefisien beta unstandardized sebesar 0,550 dan tingkat signifikansi 0,000 yang lebih kecil dari 0,05. Hal ini menunjukkan bahwa luas lahan berpengaruh terhadap pendapatan Pengembangan Usaha Mina Pedesaan Perikanan Budidaya (PUMPPB) di Kabupaten Bulukumba. Dengan demikian dapat di katakana bahwa semakin luas lahan yang di kelolah dalam bertani tambak maka semakin banyak pula pendapatan yang di peroleh petani tambak. Sebaliknya jika makin sempit lahan yang di kelolah dalam usaha tani tambak maka semakin sedikit pula pendapatan yang di peroleh petani tambak.

\section{Pengaruh Tingkat pengalaman Terhadap Pendapatan Pengembangan Usaha Mina Pedesaan Perikanan Budidaya (PUMP-PB)}

Berdasarkan tabel di atas dapat dilihat bahwa variabel tingkat pengalaman memiliki $\mathrm{t}$ hitung sebesar 2,116 > t tabel sebesar 1,9861 dengan koefisien beta unstandardized sebesar 0,231 dan tingkat signifikansi 0,037 yang lebih kecil dari 0,05. Hal ini menunjukkan bahwa tingkat pengalaman berpengaruh terhadap pendapatan Pengembangan Usaha Mina Pedesaan Perikanan Budidaya di Kabupaten Bulukumba. Menurut Nugraheni (2012), pengalaman diperoleh dari hasil berinteraksi dengan orang lain atau dengan lingkungannya semasa hidupnya. Bagi orang yang telah lama menggeluti pekerjaan akan lebih terampil dan cenderung menghasilkan suatu hasil yang lebih baik dari pada orang baru.

\section{KESIMPULAN}

Berdasarkan hasil penelitian ini maka dapat kami simpulkan beberapa hal antara lain :

1. Peranan Wanita Tani dalam Pengembangan Usaha Mina Pedesaan Perikanan Budidaya (PUMP-PB) di Kabupaten Bulukumba memberikan dampak positif dan pendapatan rata-rata kelompok yang menerima bantuan mengalami peningkatan pendapatan.

2. Faktor-faktor yang mempengaruhi peranan wanita tani terhadap Peningkatan Ekonomi pada kegiatan 
PUMP-PB adalah : umur, tingkat bersedia memberikan informasi sehingga pendidikan, jam kerja, luas lahan, menjadi data yang sangat berharga bagi dan tingkat pengalaman, sedangkan tulisan ini. Akhir kata, kami sampaikan sifat pekerjaan dan jumlah terima kasih kepada para reviewer yang tanggungan tidak berpengaruh telah memberikan masukan yang langsung terhadap peningkatan berharga di dalam penyempurnaan pendapatan wanita tani pada kegiatan tulisan ini. Tulisan ini masih jauh dari PUMP-PB.

\section{SARAN}

Dari kesimpulan di atas, maka adapun saran peneliti yaitu perlunya perhatian dari stakeholder dalam hal ini pemerintah baik pust maupun daerah pada aspek sosial budaya ekonomi, teknologi, kelembagaan dan hukum untuk lebih meningkatkan tingkat pengetahuan teknologi dan pendapatan masyarakat kelompok Pengembangan Usaha Mina Pedesaan Perikanan budidaya (PUMP-PB) yang ada di Kabupaten Bulukumba.

\section{UCAPAN TERIMA KASIH}

Hasil kajian ini merupakan bagian dari penelitian Tesis dan penulis mengucapkan terima kasih kepada Ketua Prodi Manajemen Pesisir dan Teknologi Kelautan dan Direktur Pasca Sarjana yang telah memberi kesempatan untuk melanjutkan pendidikan di PPS UMI. Terima kasih juga kami sampaikan kepada para informan yang telah kata sempurna, untuk itu saran dan masukan dari para pembaca sangat kami harapkan untuk perbaikan di kemudian hari.

\section{DAFTAR PUSTAKA}

Dinas Kelautan dan Perikanan Provinsi Sulawesi Selatan, 2019. Buku Laporan Tahunan Statistik Tahun 2019.

Direktorat Usaha Budidaya, DJPB Kementerian Kelautan dan Perikanan R.I, 2013 Pedoman Teknis Pengembangan Usaha Mina Pedesaan Perikanan (PUMP-PB)

Direktorat Usaha Budidaya, DJPB Kementerian Kelautan dan Perikanan R.I, 2014 Pedoman Teknis Pengembangan Usaha Mina Pedesaan Perikanan (PUMP-PB)

Direktorat Usaha Budidaya, DJPB

Kementerian Kelautan dan

Perikanan R.I, 2015 Pedoman

Teknis Pengembangan Usaha Mina Pedesaan Perikanan (PUMP-PB)

Irawan, K. Omori, Kikutani. 1998. Studies on The Salinity and Desiecation tolerances of Helice, triden and Helice Japonica.

Kusnadi. 2013. Akar Kemiskinan Nelayan. Yogyakarta: LKIS.

Nugraheni, S. 2012. Peran dan Potensi

Wanita dalam Pemenuhan

Kebutuhan Ekonomi Keluarga 
Nelayan. Journal of Educational Sosial Studies (JESS) Vol. 1, No. 2: 104-111

Nurlaili dan Muhartono, R. 2017. Peran Perempuan Nelayan Dalam Usaha Perikanan Tangkap Dan Peningkatan Ekonomi Rumah Tangga Pesisir Teluk Jakarta. Balai Besar Riset Sosial Ekonomi Kelautan Dan Perikanan. Jakarta Utara, Indonesia.

Suratiyah. 1991. Wanita dan Penyimpanan . Jawa Post 20 April 1991.

Soepono, M. 2009. Pengembangan Sumber Daya Manusia dan
Produktivitas, Duta Rimba,JanuariPebruari, Hal.175-176.

Sudaryanti, N. 2009. Faktor-faktor yang Mempengaruhi Ketepatan Waktu Pelaporan Keuangan Perusahaan Manufaktur di Bursa Efek Indonesia, Skripsi (tidak dipublikasikan), Program Sarjana Universitas Diponegoro, Semarang.

Taryono,. 2004. Kontribusi Peran Perempuan Dalam Pengelolaan Usaha Buoioaya dan Penanganan Pasca Panen Rumput Laut 01 Pulau Nusa Penioa, Kecamatan Nusa Penioa, Kabupaten Klungkung, Propinsi Bau. 